Issledovatel'skiy Zhurnal Russkogo Yazyka i Literatury, Vol. 9, Issue 2, 2021, Pp: 169-189

DOI: 10.52547/iarll.18.169 DOR: 20.1001.1.23452498.2021.9.2.9.7

Article No.: 18.91.20212.169189

Scientific Article

\title{
The Spread of Persian Literature in Russia: Methods, Technology and Importance
}

\author{
Motamednia Masoumeh ${ }^{1 \text { * }}$ \\ Associate professor in the Department of Russian Language, University of \\ Mazandaran, \\ Babolsar, Mazandaran.
}

(date of receiving: March, 2021; date of acceptance: July, 2021)

\begin{abstract}
The article explains the main points of the importance of studying Persian literature in Russia at the present stage, namely: the state of Russian - Iranian relations, the strengthening of intercultural dialogue between countries. The main methods of studying Persian literature that is used in leading Russian educational institutions (for example, Moscow State University, Ural State University) are presented. These are standards for teaching foreign literature, special reading of a work, and analysis of an art work, game methods and creative tasks. Advantages and disadvantages are noted for each presented method. Modern methods of mastering Persian literature by Russian readers that have become popular due to the development of Internet technologies are listed: online courses, online writing, communication in social networks with native speakers, video lessons, use of special applications, etc. And the most effective methods of learning Persian literature are offered to Russian language learners.
\end{abstract}

Keywords: Persian Literature, Russia, Russian - Iranian Relations, Methods, Persian Language.

1. E-mail: m.motamednia@umz.ac.ir *Corresponding author 
Issledovatel'skiy Zhurnal Russkogo Yazyka i Literatury, Vol. 9, Issue 2, 2021, Pp: 169-189

DOI: 10.52547/iarll.18.169 DOR: 20.1001.1.23452498.2021.9.2.9.7

Article No.: 18.91.20212.169189

\title{
Персидская литература в России: методики, приёмы,
} значимость

\author{
Мотамедния Масуме ${ }^{1 *}$ \\ Доцент кафедры русского языка Мазандаранского университета, \\ Баболсар, Мазандаран.
}

(дата получения: март 2021 г.; дата принятия: июнь 2021 г.)

\begin{abstract}
Аннотация
В статье рассматриваются основные положения, которые объясняют значимость изучения персидской литературы в России на современном этапе, а именно: состояние российско-иранских отношений, усиление межкультурного диалога между странами. Представлены основные методики изучения персидской литературы, которые применяются в ведущих российских учебных заведениях (на примере МГУ, Уральского государственного университета): это стандарты преподавания зарубежной литературы, специального чтения произведения, анализа художественного произведения, игровые способы и творческие задания. По каждой представленной методике отмечены достоинства и недостатки. Перечислены современные приёмы освоения персидской литературы российскими читателями, ставшие популярными за счёт развития интернет-технологий: онлайнкурсы,онлайн-прописи, общение в социальных сетях с носителями языка, видеоуроки, использование специальных приложений и т.д. Сделаны выводы о наиболее эффективных способах освоения персидской литературы россиянами.
\end{abstract}

Ключевые слова: Персидская Литература, Россия, Российско-Иранские Отношения, Методики, Персидский Язык.

1. E-mail: m.motamednia@umz.ac.ir * Ответственный автор 


\section{Введение}

Современная эпоха глобализации позволяет каждому человеку, имеющему доступ к сети Интернет, освоить литературное произведение на любом языке. Это можно осуществить как посредством чтения оригинала либо перевода произведения, так и путём самостоятельного его перевода при помощи специальных интернет-приложений.

Особой популярностью среди читателей во всём мире пользуются произведения классической литературы, преимущественно написанные на английском, немецком и других европейских языках, большой интерес вызывает также русская классика. Однако сегодня отмечается мода на восточную культуру: это проявляется в увлечении молодёжи всего мира восточными фильмами, музыкой, комиксами, другими произведениями искусства. Среди населения старшей возрастной категории также заметен интерес к восточной культуре (кухня, медицина, йога и проч.). Поэтому можно предположить, что и восточная литература вскоре будет активнее изучаться населением планеты. В том числе это касается и персидской литературы, авторы которой излагают свои мысли на языке фарси, принадлежащем к группе иранских языков индоевропейской группы.

В настоящее время персидская литература в большей степени распространена в таких странах, как: Иран, Таджикстан, Афганистан, и др. Потенциал к её популяризации в будущем имеется в государствах Средней и Центральной Азии и России. Это обусловлено не только территориальным фактором, но и факторами политических взаимоотношений, межкультурным обменом, налаженным странами, а также веяниями моды, которая имеется и в литературе. Именно эти факты объясняют актуальность исследуемой темы.

Цель исследования - представить методики и приёмы освоения персидской литературы в России. 
Задачи исследования:

1) определить значимость процедуры освоения персидской литературы для россиян;

2) изучить основные методики по освоению персидской литературы, принятые в России;

3) предложить современные приёмы для освоения персидской литературы в России.

\section{Основная часть}

Время возникновения персидской литературы совпадает с моментом зарождения персидского языка, который имеет достаточно древнюю историю. Первые древнеперсидские литературные произведения были зафиксированы в VI веке до н.э. С принятием иранцами ислама персидская литература пополнилась религиозными произведениями, которые стали распространяться за пределами государства - в Афганистане и Индии, в странах Средней Азии и Закавказье. Помимо религиозных трактатов и учений, персидская литература внесла вклад в мировую культуру благодаря произведениям Омара Хайяма, Хафиза, Саади, Рудаки, Фирдоуси, Руми, Аттара и других.

В конце XIX- начале XX века в персидской литературе получил развитие жанр прозы. Такие авторы, как Садег Хедаят, Мохаммад-Али Джамаль-заде, Джалаль Аль-Ахмад, Хосрову Шахани, Ахмад Махмуд создали неповторимый слог и передали читателям восточный колорит. Помимо прозаиков в персидской литературе имеются известные поэты - это Сохраб Сепехри, Ахмад Шамлу, Форуг Фаррохзад. Неповторимость их мышления, острота выражений, лаконичность, присущая всем восточным поэтам, принесли этим авторам популярность и читательскую любовь.

В России интерес к персидской литературе стал проявляться в XVIII-XIX веках, явившись следствием всплеска общемирового увлечения восточной 
культурой. Первые произведения персидских авторов в России были представлены переводами на европейские языки - немецкий и французский. Собственная переводческая работа стала осуществляться лишь в XX веке, в эпоху СССР. Это объяснялось политическими причинами: в состав государства вошёл Таджикистан, большая часть литературных произведений которого была создана именно на персидском языке, ввиду чего эти произведения были причислены к литературе народов СССР. По этой причине началась активная работа по переводу персидских произведений и их публикации в советских журналах, рассчитанных на массового читателя. Перевод трудов великих таджикских авторов был объявлен делом государственной важности.

Однако цензура и идеологический отбор, который был присущ практически всей литературе в СССР, не позволяли публиковать огромное количество интересных персидских произведений. Ситуация изменилась после распада Советского Союза. Активнее, чем прежде, стали распространяться труды Фарид ад-Дина Аттара и Джалал ад-Дина Руми. Особенную любовь читателей в России завоевал Омар Хайям, переводы трудов которого стали издаваться в виде отдельных сборников цитат и вошли в рейтинг самых приобретаемых россиянами книг.

Омар Хайям (профессиональные иранисты используют более точную транслитерацию -Хаййам) стал самым известным в западном мире представителем классической персидской поэзии. Его произведения издаются большими тиражами, цитируются, переводятся на новые языки. Хотя реальный Гийас ад-Дин Абу-л-Фатх Омар ибн Ибрахим Хайям (1048 - 1131) прославился при жизни и в веках прежде всего как математик и астроном. Но в то время всякий уважающий себя философ складывал четверостишия рубайи. (Чалисова 2016. Электронный ресурс)

Чтобы понять культуру любой нации, необходимо исследовать её обычаи, традиции, историю и литературу. В настоящее время Россия и Иран являются 
стратегически важными партнёрами друг для друга. Это проявляется как в торговом, так и в военном сотрудничестве, а также в ряде других областей.

В течение последних лет Россия и Иран находятся в особенно тесном союзе, через культурный диалог к взаимопроникновению культур. Единство стратегических целей и политических задач двух наших стран в регионе Ближнего Востока, множество точек соприкосновения по вопросам ведения диалога с западным миром - всё это свидетельствует о долгосрочности отношений в перспективе. Именно поэтому расширяются работы по межкультурному обмену для укрепления связей двух государств.

Примером межкультурного обмена можно назвать масштабную конференцию, которая прошла в 2019 году в рамках Российско-иранского культурного диалога. (EurAsia Daily 2019. Электронный ресурс). Представители Ирана отметили важность для них фигуры Л.Н. Толстого, а сами провели масштабные чтения по теме «Ислам в глобальном мире: мусульманское наследие и межкультурный диалог». (РИА Новости. Александр Вильф 2019. Электронный ресурс) .

Также в 2019 году между ведущими университетами России и Ирана было проведено четыре литературных конференции, организовано несколько международных книжных выставок.

В 2020 году из-за пандемии коронавируса страны продолжили культурный диалог, но он проводился в онлайн-режиме .

Современные политологи и эксперты в области международных отношений отмечают, что от того, как страны сумеют наладить диалог и взаимопонимание, зависит дальнейшая судьба государств, т.к. российскоиранские связи сейчас как никогда крепки и важны. Подсказать подход к налаживанию культурного диалога между россиянами, и иранцами могут литературные классики России и Ирана. Именно поэтому высока значимость освоения персидской литературы в России. 
Стоит отметить, что персидская литература преподаётся чаще всего в специализированных высших учебных заведениях (направления «Востоковедение и африканистика», «Зарубежная филология», «Международные отношения» и т.п.). Зачастую курс идёт параллельно изучению персидского языка.

В России история преподавания этого языка берёт начало в XX веке. Например, в 1913 году был издан первый персидско-русский словарь, в 1920-х гг. в Ленинграде в Институте востоковедения Ленинградского университета была учреждена кафедра персидского языка. Благодаря этому событию вышло несколько учебных пособий по персидскому языку (авторы - Бертельс, Касаева, Заркова). В 1950-е гг. учебные пособия по изучению персидского языка были обновилены и дополнены такими авторами, как: Восканян, Рубинчик, Алиее, Пейсиков, Овчинникова.

Из современных авторов учебных пособий по персидскому языку можно назвать В.Б. Иванова, Е.Л. Гладкову, К.И. Полякова, А.А. Носырева, Г.Г. Наджафова.

Рассмотрим методику освоения персидской литературы в России на примере МГУ им. Ломоносова.

В МГУ им. Ломоносова персидская литература преподносится студентам весьма обширно. Лекционный материал охватывает не только творчество известных в России и Европе классиков (Хайяма, Фирдоуси, Саади, Хафиза, Низами), но и менее популярных авторов.

В лекциях освещаются проблемы функционирования поэтического канона и на примере персидской классической литературы характеризуются базовые законы нормативной поэтики, а также области проявления индивидуально-авторской инициативы в условиях традиционалистского типа словесного творчества.

Материал преподносится по принципу эволюции развития персидской литературы: от её зарождения до наивысшего расцвета. Кроме того, делаются акценты на основных жанровых видах поэзии. 
Персидская литература в МГУ им. Ломоносова преподаётся для студентовфилологов, а также для узких специалистов, которые изучают литературу Ближнего и Среднего Востока, для историков, искусствоведов и литературоведов.

Стандартная методика преподавания персидской литературы в российских учебных заведениях выглядит следующим образом:

- лекции (в т.ч. дистанционные);

- представление аудиозаписей или видеозаписей по изучаемой тематике;

- творческие задания;

- открытые рассуждения.

Стандартное построение лекций по освоению персидской литературы в российских высших учебных учреждениях:

1) вводная часть: обучающиеся узнают об основных факторах формирования литературы на персидском языке;

2) преподносится материал о творчестве Рудаки и его современников;

3) подробным образом изучается Фирдоуси, его творчество и его место в истории персидской литературы;

4) даётся материал о придворной поэзии XI века, в составе которой следующие авторы: Унсури, Фаррохи, Манучихри. Помимо сущности текстов разбираются принципы творчества;

5) продолжение изучения персидской литературы XI века на примере любовно-романического эпоса;

6) проводится лекция о влиянии религиозных течений на направления персидской литературы. В качестве примера изучаются произведения суфийских поэтов; 
7) даётся материал о придворной поэзии 12 века, в составе которой следующие авторы: Муиззи, Анвари, Хакани. Делается акцент на появлении творческой индивидуальности;

8) изучается мистическое направление в персидской литературе на примере творчества Санаи;

9) изучаются региональные традиции персидской литературы на примере творчества Низами;

10) проводится цикл лекций о великом классике персидской литературы Омаре Хайяме и особенностях его творчества;

11) преподносится материал об эпической и лирической персидской литературе на примере творчества Фарид ад-Дина Аттара;

12 ) изучается литературная эпоха Саади и его современников;

13) рассматривается процесс распространения персидского языка в других странах, становление персоязычной литературы в Индии на примере творчества Амира Хосрова Дехлеви;

14) изучается литературная эпоха Хафиза: особенности и нюансы произведений;

15) преподносится материал о персидской классической прозе XI-XII веков;

16) даётся цикл лекций о трансформации персидской литературы со времён Средневековья до нашего времени.

По итогам освоения персидской литературы с помощью данной методики обучающийся будет знать особенности становления персидской литературы в условиях появления ислама, основные этапы развития персидской литературы и характеристики выдающихся произведений.

Обучающийся сможет самостоятельно работать с научной литературой по истории персидской литературы, анализировать прочитанный материал и формировать обоснованное мнение по проблемам развития литературы. 
По итогам курса у обучающегося будут иметься:

- базовые представления о теоретических основах литературного процесса и культурной традиции в регионе распространения персидского языка;

- базовые представления о методах исследования литератур и культур Востока;

- знание литературы и фольклора в их историческом развитии и современном состоянии, в сопряжении с гражданской историей и историей культуры народа, говорящего на персидском языке;

- навыки пользования основными методами литературоведческого анализа. (https://online.sev.msu.ru/kursy/kursy-dlyastudentov/klassicheskaya-persidskaya-literatura/)

Достоинства представленной методики:

- стандартный формат восприятия информации;

- выборочность материала позволяет охватить наиболее значимые произведения, уложившись в отведённое время для изучения материала;

- подкрепление материала средствами визуализации информации;

- повышение уровня знания языка.

Недостатки методики:

- сложность восприятия информации для лиц с низким уровнем персидского языка;

- отсутствие возможности освоить произведения авторов, не входящих в состав перечисленных в курсе.

Если рассматривается отдельно взятое литературное произведение на персидском языке, то типовая методика освоения состоит из следующих этапов:

1) знакомство с эпохой написания; 
2) подача информации об авторе, основах его мировоззрения, общественной и эстетической позиции;

3) подача информации об истории создания произведения;

4) создание установки на восприятие произведения;

5) знакомство с ключевой лексикой произведения;

6) определение жанровых особенностей произведения;

7) обсуждение произведения, определение его места в творчестве автора, в персидской и мировой литературе.

Достоинства методики:

- всеобъемлющий охват материала, позволяющий всесторонне проникнуться произведением;

- повышение уровня знания персидского языка за счёт разбора фраз и цитат.

Недостатки методики:

- навязывание преподавателем определённого мнения относительно происходящих событий или героев произведения;

- приводит к шаблонности восприятия других литературных произведений.

Применительно к отдельно взятому произведению персидской литературы может применяться методика изучающего чтения. Эта методика заключается в том, что преподаватель добивается от обучающегося максимального понимания информации.

Этапы методики:

$$
\begin{aligned}
& \text { - медленное чтение литературного произведения; } \\
& \text { - осмысление текста и сопереживание; } \\
& \text { - обсуждение. }
\end{aligned}
$$


Особенность методики заключается в том, что перед прочтением произведения преподаватель должен заранее провести работу по наиболее сложным словам, фразам, отрывкам текста, объяснив значение и трактовку.

Также можно заранее вынести несколько цитат, чтобы повысить интерес обучающихся к персидскому произведению.

В состав методики входит работа преподавателя в аудитории:

1) преподаватель должен прокомментировать начало произведения, спросив о том, понятен ли читателям язык, формы и литературные обороты;

2) преподаватель должен обратить внимание читателей на основные эпизоды литературного произведения.

Достоинствами данной методики являются:

- индивидуальный подход преподавателя к обучающимся;

- нейтрализация языкового барьера;

- акцент на литературном произведении, а не на эпохе, биографии автора и прочих моментах.

Недостатками методики можно назвать:

- снижение самостоятельности мышления и критичности обучающихся;

- невозможность использования при отсутствии базовых знаний языка.

Ещё одна методика освоения персидской литературы в России - это анализ художественного произведения. Этапы её реализации (Якибова 2012. 151):

1) выделяется идейно-нравственная система ценностей произведения, подробным образом обсуждается и анализируется;

2) определяется образно-эстетическая система произведения;

3) выявляется духовный потенциал произведения;

4) выискиваются ментальные черты произведения персидского автора, отражающие особенности национального характера. 
Достоинства методики:

- углубленное изучение материала с позиций лингвистики и литературоведения;

- развитие критичности мышления.

Недостатки методики:

- сложность для новичков;

- невозможность использования при отсутствии базовых знаний языка.

В российских учебных заведениях зачастую по курсу изучения персидской литературы применяют методику чтения Ильи Франка. Это метод обучающего чтения, который предполагает освоение информации за счёт параллельного чтения на родном и иностранном языке. Автор методики обещает эффект от регулярных занятий - достижение свободного чтения литературы за 5 месяцев.

Основа методики Ильи Франка заключается в том, что обучение осуществляется на базе неадаптированного текста на языке оригинала. В зависимости от уровня сложности это могут быть афоризмы, цитаты, детские сказки, рассказы, классические романы или публицистические статьи. Сначала небольшой отрывок текста объясняется по фразам (https://online.sev.msu.ru/kursy/kursy-dlya-studentov/klassicheskaya-persidskayaliteratura/):

1) транслируется фраза или предложение на персидском языке;

2) даётся транскрипция фразы или предложения на персидском языке;

3) происходит объяснение новых слов;

4) грамматика;

5) транслируется следующая фраза текста;

6) после нескольких фраз весь отрывок теста даётся на языке оригинала без комментариев. 
Приведённый текст на персидском языке необходимо прочесть несколько раз: сначала текст с подсказками, а если есть аудиозапись - то прослушать ещё и её, а затем читать оригинал. Если же у обучающегося имеются определённые знания языка, то можно делать наоборот: читать неадаптированный вариант текста, а затем можно при необходимости вернуться к тексту с подсказками. Новые слова и грамматические конструкции при таком подходе запоминаются автоматически, по мере повторяемости их в тексте. Главное в такой методике - объёмное и регулярное чтение.

Однако такая методика подвергается критике. Некоторые пользователи считают, что она не позволяет достигнуть должного эффекта, если базовые знания языка практически нулевые. Кроме того, эта методика не подходит для совершенствования разговорной речи. Т.е. читатель персидских произведений может освоить материал в оригинале, но не сможет в дальнейшем обсудить его на должном уровне с носителями языка.

Таким образом, методика Ильи Франка требует доработок. Например, можно внести коррективы для преподавателей, которые выбирают в ходе обучения персидской литературе эту методику:

1) уровень языковой подготовки слушателей курса по освоению персидской литературы при помощи чтения по методу Ильи Франка должен быть базовым, т.е. обучающийся уже должен владеть грамматикой и базовым словарным запасом;

2) скорость чтения должна быть медленной, а один отрывок литературного произведения необходимо повторять несколько раз вслух, что будет способствовать запоминанию новых слов и фраз, а также его осмыслению;

3) особенно важные отрывки произведения следует выписывать отдельно на родном и персидском языке;

4) метод Ильи Франка следует комбинировать с другими методиками освоения персидской литературы: прослушивание аудиозаписей, обсуждение темы с экспертами - носителями языка и т.д. 
В Уральском федеральном университете сложилась своеобразная методика преподавания персидской литературы и зарубежной литературы в целом. К традиционной форме преподавания материала добавляется система практических занятий в виде игр. Эта методика работает следующим образом:(Назарова 2010. 79)

1) группы обучающихся разбиваются на подгруппы после прочтения определённого произведения персидской литературы. Им выдаётся задание по созданию сценария телеигры по аналогу популярных ТВ-передач на российском телевидении (например, «Своя игра»). В таких заданиях отрабатывается группа вопросов по произведению с разбивкой на тематики: «Жизнь автора», «Эпоха автора», «Герои произведения» и т.д.

После проведения игры идёт обсуждение и оценка. Оценка выставляется по ряду критериев: уровень использования текста произведения, интерес подобранных вопросов, зрелищность;

2) вариант изучения персидской литературы в формате журналистского расследования в виде поиска ответа на заранее поставленный вопрос по конкретной ситуации произведения.

После презентации ответа выставляется оценка по критериям достоверности и убедительности версии;

3) игра на основе ТВ-шоу в формате таких российских передач, как «Пусть говорят», т.е. обучающиеся должны поставить вопрос по произведению, написать сценарий к его обсуждению, сформировать команды, поддерживающие полярные версии по отношению к событию, герою, автору и т.д.

После проведения игры производится оценка по критериям соответствия тематики представления и произведения, убедительности аргументов;

4) задания по разработке рекламы произведения персидской литературы или его презентации для разных категорий читателей. 
Достоинствами подобной методики являются:

- повышение интереса обучающихся к материалу;

- развитие самостоятельности мышления;

- повышение креативности и уровня владения новыми

технологиями;

- развитие качества «работа в команде».

Недостатками методики можно назвать:

- сложность внедрения формата при отсутствии аналогичного опыта;

- снижение языковых знаний, т.к. предполагается проведение всех занятий в этом формате на родном языке.

Современные приёмы освоения персидской литературы тесно связаны с интернет-технологиями. Модным веянием сейчас становится прочтение (просмотр) оригинала произведения. Поэтому встаёт вопрос об изучении персидского языка. Для этого в настоящее время существует несколько вариантов:

- во-первых, это самостоятельное изучение языка «с нуля» при помощи видеоуроков. Подобные уроки можно найти на сайте университета Даларны (Швеция). Уроки состоят из видеороликов длительностью от 7 до 18 минут, где подробным образом представляется информация об алфавите и особенностях письменности, о лексике, временах и прочих правилах. Информация подробна, удобна для восприятия, красочна и образна.

Для россиян Фонд Саади разработал инновационную методику изучения персидского языка. Этот фонд специализируется на стандартизации персидского языка по всему миру, т.к. считается, что освоению литературы мешает именно языковой барьер.

Новое инновационное пособие, изданное Фондом Саади, предназначено для тех, кто только приступил к изучению персидского языка. Алфавит 
изучается на основе рассмотрения каждой буквы в контексте её применения. Всего в пособии 17 уроков, созданных по единому образцу. (http://www.franklang.ru / index.php / persidskij-yazyk / ).

В настоящее время в Центре персидского языка в открытом доступе имеется литература по его изучению, в т.ч. на английском языке, представлены интересные литературные произведения на персидском языке, действует запись на языковые курсы;

- во-вторых, для более глубокого изучения персидского языка и, соответственно, литературы на персидском языке в настоящее время разработаны технологии цифровых прописей. Специализированные сайты предлагают медленную визуализацию написания букв - в зависимости от того, в каком месте она стоит: в начале - середине - конце слова;

- в-третьих, это адаптация к персидскому языку при помощи радио. Специализированные образовательные сайты выкладывают отрывки из новостей страны, которые ведущие могут читать медленнее, чем обычно, - для иностранцев, изучающих язык. К каждому сюжету прилагается словарь, который позволяет сразу узнать новое слово, прослушать его от носителя языка. А те, кто уже обладает базовыми знаниями персидского языка, смогут оценить особенности построения диалогов, споров, речевых оборотов, что позволит им стать ближе к освоению культуры и литературы персидских авторов;

- в-четвёртых, существует масса специализированных сервисов, например, Mylanguageexchange - это международный сервис, где можно найти носителя языка, который поможет в освоении литературы. На сайте помимо такой возможности представлена и методическая база: библиотека материалов, блок для записей, текстовый чат и чат для тренировки произношения и т.д.;

- в-пятых, для российских читателей персидских произведений и желающих изучить этот язык существуют русскоязычные сайты, с помощью которых можно повысить свои знания: улучшить скорость чтения, скорость 
понимания языка за счёт просмотра развлекательных программ и прослушивания аудиозаписей.

Также российские читатели могут воспользоваться крупнейшей социальной сетью (busuu.com). Сайт разработан профессиональными лингвистами, и благодаря ему можно быстро научиться читать, понимать и говорить. В основе работы лежит принцип взаимного обучения. Аналогичный принцип заложен в основе виртуального онлайн-сообщества livemocha.com.

Некоторые сайты для россиян, желающих освоить персидскую литературу, платные. Например, это онлайн-сервис italki.com. Этот сервис помогает найти профессионального преподавателя - носителя языка по заданной теме. После выбора преподавателя заключается договор о расписании уроков, о тематике и направлении (в данном случае о персидской литературе, персидских поэтах и писателях).

\section{Заключение}

Подводя итоги исследования методики и приёмов освоения персидской литературы в России, можно сделать определённые выводы. Единого и стандартизированного варианта по освоению произведений персидской литературы не имеется. Каждое учебное заведение или индивидуум вправе самостоятельно решать, какой методикой воспользоваться. Наилучшим вариантом можно назвать классическое аудиторное преподавание в виде лекций с прочтением произведений на оригинальном языке. Такую методику следует дополнять занятиями в виде игр по содержанию и сюжету произведения для лучшего усвоения материала. Параллельно обязательно изучение персидского языка - для этого наиболее эффективным вариантом будет получение интернет-уроков от носителя языка, обсуждение произведения с экспертами - носителями языка и повышение знаний по методике чтения Ильи Франка. 


\section{Литература}

1- Лидеры мусульманских общин обсудят в Москве проблемы мирового ислама. [Электронный ресурс]. https://ria.ru/20190924/1559024573.html- Дата доступа: 19.03.2021.

2- Ломоносов центр компетенций в области онлайн-обучения- [Электронный pecypc]. - Режим доступа: https://online.sev.msu.ru/kursy/kursy-dlyastudentov/klassicheskaya-persidskaya-literatura/- Дата доступа: 15.02.2021.

3- Метод чтения Ильи Франка. - [Электронный ресурс]. - Режим доступа: http://www.franklang.ru / index.php / persidskij-yazyk / - Дата доступа: 22.03.2021.

4- Назарова Л. А. (2010). Зарубежная литература в вузе: инновации, методика, проблемы преподавания и изучения: Сборник статей. - Екатеринбург.

5- Россия и Иран: через культурный диалог к взаимопроникновению культур. [Электронный ресурс]. - Режим доступа: https://eadaily.com / ru / news / 2019 / 09 / 26 / rossiya-i-iran-cherez-kulturnyy-dialog-k-vzaimoproniknoveniyu-kulturДата доступа: 12.03.2021.

6- Чалисова Н. (2016). Омар Хайям и его переводчики - [Электронный ресурс]. Режим доступа: (https://polit.ru/article/2016/05/27/ps_chalisova/)- Дата доступа: 11.02.2021.

7- Якибова Д.У. (2012). Методика преподавания литературы: учеб. пособие для студентов филологических факультетов. 2-е изд., испр. и доп. / Д.У. Якибова. - М.: РУДН

\section{Bibliography}

1- Lidery musul'manskih obshhin obsudjat $v$ Moskve problemy mirovogo islama. [Jelektronnyj resurs]. - Rezhim dostupa: https://ria.ru/20190924/1559024573.htmlData dostupa: 19.03.2021.

2- Lomonosov centr kompetencij v oblasti onlajn-obuchenija- [Jelektronnyj resurs]. Rezhim dostupa: https:/online.sev.msu.ru/kursy/kursy-dlya-studentov/ klassicheskaya-persidskaya-literatura/- Data dostupa: 15.02.2021.

3- Metod chtenija Il'i Franka. - [Jelektronnyj resurs]. - Rezhim dostupa: http://www.franklang.ru / index.php / persidskij-yazyk / - Data dostupa: 22.03.2021.

4- Nazarova L.A. (2010). Zarubezhnaja literatura v vuze: innovacii, metodika, problemy prepodavanija i izuchenija: Sbornik statej. - Ekaterinburg. 
5- Rossija $i$ Iran: cherez kul'turnyj dialog $k$ vzaimoproniknoveniju kul'tur. [Jelektronnyj resurs]. - Rezhim dostupa: https:/eadaily.com / ru / news / 2019 / 09 / 26 / rossiya-i-iran-cherez-kulturnyy-dialog-k-vzaimoproniknoveniyu-kultur- Data dostupa: 12.03.2021.

6- Chalisova N. (2016). Omar Hajjam i ego perevodchiki - [Jelektronnyj resurs]. Rezhim dostupa: (https://polit.ru/article/2016/05/27/ps_chalisova/)- Data dostupa: 11.02.2021.

7- Jakibova D.U. (2012). Metodika prepodavanija literatury: ucheb. posobie dlja studentov filologicheskih fakul'tetov. 2-e izd., ispr. i dop. / D.U. Jakibova. - M.: RUDN

\section{HOW TO CITE THIS ARTICLE}

Motamednia M. (2021). The Spread of Persian Literature in Russia: Methods, Technology and Importance. Issledovatel'skiy Zhurnal Russkogo Yazyka I Literatury, 9(2), 169-189.

DOI: $10.52547 /$ iarll.18.169

URL: https://www.journaliarll.ir/index.php/iarll/article/view/204 


\title{
گسترش ادبيات فارسى در روسيه: روشها، فن آورى و اهميت
}

\author{
معصومه معتمدنيا

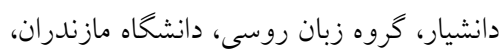 \\ بابلسر، مازندران.

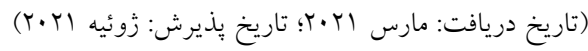

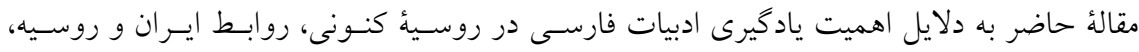

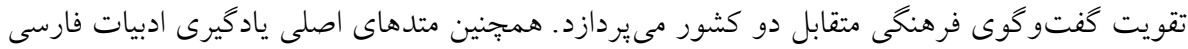

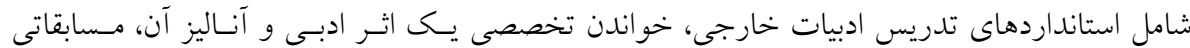

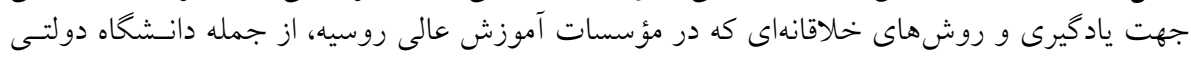

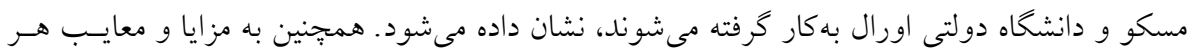

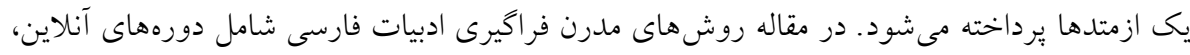

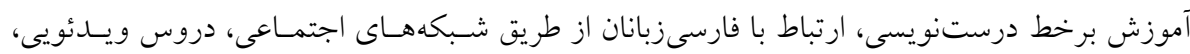

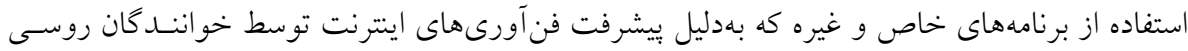

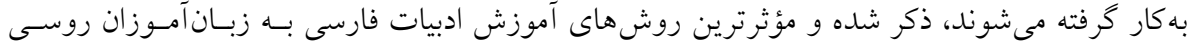
ارائه مى شود.

وازگّان كليدى: ادبيات فارسى، روسيه، روابط ايران و روسيه، متدها، زبان فارسى.

1. E-mail: m.motamednia@umz.ac.ir نويسنده مسئول * نوع مقاله: علمى - يزووهشى 